\title{
Antiallergic Effect of Flavonoid Glycosides Obtained from Mentha piperita $\mathbf{L}$.
}

\author{
Toshio Inoue, ${ }^{a, b}$ Yukio Sugimoto, ${ }^{a}$ Hideki Masuda, ${ }^{b}$ and Chiaki KameI ${ }^{*, a}$ \\ Department of Pharmacology, Faculty of Pharmaceutical Sciences, Okayama University, ${ }^{a}$ 1-1-1 Tsushima-naka, \\ Okayama 700-8530, Japan and Ogawa \& Co., Ltd., Material R\&D Laboratory, ${ }^{b}$ 15-7 Chidori, Urayasu, Chiba 279-0032, \\ Japan. Received August 13, 2001; accepted October 31, 2001
}

\begin{abstract}
Six flavonoid glycosides, eriocitrin (1), narirutin (2), hesperidin (3), luteolin-7-O-rutinoside (4), isorhoifolin (5), diosmin (6), rosmarinic acid (7) and 5,7-dihydroxycromone-7-O-rutinoside (8), were isolated from the aerial part of Mentha piperita $\mathrm{L}$. Among these compounds, compound 4 showed a potent inhibitory effect on histamine release induced by compound $48 / 80$ and antigen-antibody reaction. This compound was more effective than luteolin and luteolin-7-O-glucoside in inhibiting histamine release from rat peritoneal mast cells. Compound 4 also caused a dose-related inhibition of the antigen-induced nasal response and significant effects were observed at doses of 100 and $300 \mathrm{mg} / \mathrm{kg}$. These results indicate that compound 4 may be clinically useful in alleviating the nasal symptoms of allergic rhinitis.
\end{abstract}

Key words Mentha piperita L.; flavonoid glycoside; antiallergic effect; rat peritoneal mast cell; histamine

Peppermint (Mentha piperita L.) belonging to the labiatae family is commercially cultivated in the temperate zones around the world, particularly in the United States, Canada and China, for its volatile oil, obtained by steam distillation from the plant's aerial parts. ${ }^{1)}$ The volatile constituents (essential oil) obtained by steam distillation from the aerial parts have been widely used for a long time because its flavor, fragrance and carminative and stimulant properties. In addition, the volatile oil has been reported to show anti-inflammatory, antibacterial and antifungal properties. ${ }^{2-4)}$ As described above, the broad spectrum of bioactivity of this plant has usually been ascribed to the components of its essential oil. However, only a few studies have reported the quantitative and qualitative composition of the non-volatile constituents. ${ }^{5,6)}$

We have reported that the $50 \% \mathrm{EtOH}$ extract of peppermint inhibited histamine release from rat peritoneal mast cells induced by compound 48/80. A remarkable inhibition against nasal symptoms (sneezing and nasal rubbing) induced by antigen challenge was also recognized by the $50 \%$ EtOH extract of peppermint in actively sensitized rats. ${ }^{7}$ However, the true characters of the effective component contained in this extract were not clarified. Therefore, the present study was undertaken to clarify the anti-allergic effects of certain compounds isolated from the extract of the peppermint.

\section{MATERIALS AND METHODS}

Apparatus The NMR spectra were measured using a Bruker AVANCE-400 NMR spectrometer. The spectral data are reported as ppm downfield from tetramethylsilane (TMS) $(\delta=0)$. Preparative HPLC was performed using a Soken Hisep LC type C (Soken Chemical \& Engineering Co., Ltd., Tokyo, Japan). TLC was performed on silica gel $60 \mathrm{~F}_{254}$ plates (Merck, Darmstadt, Germany). TLC spots were detected with $10 \% \mathrm{H}_{2} \mathrm{SO}_{4}$ followed by heating. Column chromatography was carried out on Sephadex LH-20 (Amersham Pharmacia Biotech UK, Ltd., England) and DIAION HP-20 (Mitsubishi Chem. Ind., Co., Ltd., Tokyo, Japan).

Plant Material The dried leaves of Peppermint (Mentha piperita L.) were purchased from TRI-WEST SPECIALTIES, L.L.C. (WA, U.S.A.).

Chemicals The chemicals used and their sources were as follows: Aluminum hydroxide (LSL Co., Tokyo, Japan), compound 48/80 (Sigma, St. Louis, MO, U.S.A.), gum arabic (Wako, Tokyo, Japan), o-phthaldialdehyde (Sigma), luteolin (Funakoshi, Tokyo, Japan), luteolin-7-O-glucoside (Funakoshi), ovalbumin (Sigma), oxatomide (Kyowa Hakko Kogyo Co., Ltd., Shizuoka, Japan), L- $\alpha$-phosphatidyl-L-serine (Sigma), tranilast (Kissei Pharmaceuticals Co., Ltd., Nagano, Japan).

Extraction and Isolation First, the essential oil was removed from the peppermint leaves and stems by steam distillation, and the residual leaves and stems were dried. The dried powdered leaves and stems $(5 \mathrm{~kg})$ were then extracted by refluxing in water $(751,1 \mathrm{~h})$. The filtrate was evaporated under reduced pressure to yield a dark brown extract $(1230 \mathrm{~g})$. The extract was suspended in $50 \% \mathrm{EtOH}$ and then defatted with $n$-hexane $(11 \times 6)$. After removal of the solvent, the residue that dissolved in $\mathrm{H}_{2} \mathrm{O}$ was subjected to chromatography on DIAION HP-20 (100 mm i.d., 31$)$ and successively eluted with 71 of $\mathrm{H}_{2} \mathrm{O}, 50 \% \mathrm{EtOH}$ and $\mathrm{EtOH}$. A part of the $50 \%$ EtOH eluate was further purified by column chromatography on Sephadex LH-20 (30 mm i.d., $500 \mathrm{ml})$ and eluted with increasing amounts of methanol in $\mathrm{H}_{2} \mathrm{O}$ $(1: 1-9: 1,51)$. Fractions of $100 \mathrm{ml}$ each were collected and examined by silica gel TLC $\left(\mathrm{CHCl}_{3}: \mathrm{MeOH}: \mathrm{AcOH}: \mathrm{H}_{2} \mathrm{O}=\right.$ $60: 20: 15: 5$ ). Fractions with similar $R f$ (TLC) values were combined and concentrated to afford fractions A-E. Fraction $\mathrm{C}$ was rechromatographed by HPLC $(50 \mathrm{~mm}$ i.d. column, $500 \mathrm{~mm}$ length, ODS-W $15-30 \mu \mathrm{m}$, solvent $0 \mathrm{~min}$ : $45 \% \mathrm{MeOH}, 22 \mathrm{~min}: 50 \% \mathrm{MeOH}$, flow: $100 \mathrm{ml} / \mathrm{min}$ ) to yield 5 fractions, C-1, C-2, C-3, C-4 and C-5. A part of each fraction was further purified by repeated HPLC to give $\mathbf{1}$ (6570 mg), 2 (36 mg), 3 (230 mg), 4 (3250 mg), 5 (41 mg), 6 $(93 \mathrm{mg}) 7(890 \mathrm{mg})$ and $8(420 \mathrm{mg})$, respectively.

Animals Male Wistar strain rats (age: 7 weeks; body weight: $190-220 \mathrm{~g}$ ) were obtained from Shimizu Laboratory Supplies (Kyoto, Japan). All of animals were maintained in an air-conditioned room at the controlled temperature of $24 \pm 2{ }^{\circ} \mathrm{C}$ and humidity of $45 \pm 15 \%$. The animals were al- 
lowed food and water ad libitum.

Compound 48/80-Induced Histamine Release from Isolated Rat Peritoneal Mast Cells Briefly, rat peritoneal mast cells were harvested from the abdominal cavity of the male rats and purified by Percoll density centrifugation. Physiological buffered saline (PBS; in mM: $\mathrm{NaCl} 154, \mathrm{KCl}$ 2.7, $\mathrm{CaCl}_{2} 5, N$-2-hydroxyethyl piperazine- $N$ '-2-ethanesulfonic acid (HEPES) 5; pH 7.4) was injected into the peritoneal cavity. The abdominal region was gently massaged for $90 \mathrm{~s}$ and peritoneal fluid was collected and centrifuged for $7 \mathrm{~min}$ at $100 \times \boldsymbol{g}, 4^{\circ} \mathrm{C}$. After centrifugation, the cell pellets were pooled and washed twice in $\operatorname{PBS}(-)$ solution. The mast cell pellets purified by Percoll density centrifugation for $15 \mathrm{~min}$ at $200 \times \boldsymbol{g}, 4^{\circ} \mathrm{C}$ were washed twice in $\operatorname{PBS}(-)$ solution. Thereafter, equal numbers of mast cells $\left(2.5 \times 10^{6}\right.$ cells/tube) were preincubated in $0.8 \mathrm{ml}$ of $0.1 \%$ glucose containing physiological salt solution $[\mathrm{PBS}(+)]$ for $10 \mathrm{~min}$ at $37^{\circ} \mathrm{C}$. The test drugs dissolved in $\operatorname{PBS}(+)$ were added $(0.1 \mathrm{ml}) 10 \mathrm{~min}$ before compound 48/80 (final concentration: $0.5 \mu \mathrm{g} / \mathrm{ml}$ ). The reaction was stopped $10 \mathrm{~min}$ later by cooling the tubes in ice water. The tubes were centrifuged for $15 \mathrm{~min}$ at $200 \times \boldsymbol{g}$ and the histamine content was measured in the supernatant and precipitate using an autoanalyzer as previously reported. $^{8)}$

Antigen-Induced Histamine Release from Isolated Rat Peritoneal Mast Cells Equal numbers of mast cells $(2.5 \times$ $10^{6}$ cells/tube) were preincubated in $0.7 \mathrm{ml}$ of $0.1 \%$ glucose containing physiological salt solution $[\mathrm{PBS}(+)]$ for $10 \mathrm{~min}$ at $37^{\circ} \mathrm{C}$. Thereafter, L- $\alpha$-phosphatidyl-L-serine (final concentration: $1 \mu \mathrm{g} / \mathrm{ml})$ suspended in $\operatorname{PBS}(+)$ was added $(0.1 \mathrm{ml})$ and preincubated for $5 \mathrm{~min}$. The test drugs dissolved in $\operatorname{PBS}(+)$ were added $(0.1 \mathrm{ml}) 10 \mathrm{~min}$ before ovalbumin (final concentration: $10 \mu \mathrm{g} / \mathrm{ml})$. The reaction was stopped $10 \mathrm{~min}$ later by cooling the tubes in ice water. The following procedure is the same as that of the method already described. ${ }^{8)}$

Nasal Symptoms Induced by the Antigen Rats were actively sensitized by an injection of physiological saline containing $1 \mathrm{mg}$ ovalbumin, $10^{10}$ cells of $B$. pertussis and $2 \mathrm{mg}$ of aluminum hydroxide into the four foot pads on the first day. Five days later, they were boosted by a subcutaneous injection of $1 \mathrm{ml}$ of physiological saline containing $0.5 \mathrm{mg}$ ovalbumin into the rostral parts of the back. Fourteen days later, local sensitization was performed every day by dripping ovalbumin in saline $(1 \mathrm{mg} / \mathrm{ml}, 10 \mu \mathrm{l} /$ nostril $)$ into the bilateral nasal cavities using a micropipette. The effects of the drugs on the nasal symptoms after antigen challenge were evaluated with rats from 28 to $42 \mathrm{~d}$ old after general sensitization. Before the experiment, the animals were placed in an observation cage $(32 \times 24 \times 18 \mathrm{~cm})$ for $10 \mathrm{~min}$ for acclimatization. After nasal instillation of $10 \mu \mathrm{l}$ of antigen dissolved in saline $(1 \mathrm{mg} / \mathrm{ml})$ into the bilateral nasal cavities, the animals were placed in the observation cage ( 1 animal/cage), and sneezing and nasal rubbing were counted for $30 \mathrm{~min}$. The drugs were orally administered $1 \mathrm{~h}$ before the antigen injection.

Nasal Symptoms Induced by Histamine Before the experiment, the animals were placed in an observation cage $(32 \times 24 \times 18 \mathrm{~cm})$ for $10 \mathrm{~min}$ for acclimatization. After nasal instillation of $10 \mu \mathrm{l}(10 \mu \mathrm{mol} / \mathrm{site})$ of histamine dissolved in saline into the bilateral nasal cavities, the animals were placed in the observation cage ( 1 animal/cage) and sneezing and nasal rubbing were counted for $30 \mathrm{~min}$. The drugs were orally administered $1 \mathrm{~h}$ before the histamine injection.

Statistical Analysis The data are presented as means \pm S.E.M. Statistical significance was tested by one-way analysis of variance using Dunnett's test. A probability value less than 0.05 was considered significant. The $\mathrm{IC}_{50}$ values were calculated according to the probit method.

\section{RESULTS AND DISCUSSION}

Our previous paper revealed that the $50 \%$ EtOH extract of peppermint significantly inhibited histamine release from rat peritoneal mast cells. In addition, the $50 \%$ EtOH eluate separated by DIAION HP-20 column chromatography was more effective than the $50 \%$ EtOH extract of peppermint and showed a hydrophobic property. On the other hand, hexane and the other hydrophilic fractions had less effect. ${ }^{7)}$ Therefore, it seems likely that the active compounds contained in this fraction were quite soluble in water. In the present study, therefore, the extracting solvent was replaced by hot water instead of $50 \% \mathrm{EtOH}$. The hot water extract of Mentha piperita L. was further separated into water, 50\% $\mathrm{EtOH}$, EtOH and acetone eluates by DIAION HP-20 column chromatography. From the $50 \%$ EtOH eluate, 8 compounds, i.e., eriocitrin (1), narirutin (2), hesperidin (3), luteolin-7-O-rutinoside (4), isorhoifolin (5), diosmin (6), rosmarinc acid (7) and 5,7-dihydroxycromone-7-O-rutinoside $(\mathbf{8})$ were isolated (Fig. 1). The chemical structures of these compounds were elucidated by NMR including distortionless enhancement by polarization transfer (DEPT), ${ }^{1} \mathrm{H}-{ }^{1} \mathrm{H}$-correlation spectroscopy (COSY), ${ }^{1} \mathrm{H}$-detected heteronuclear multiple quantum coherence (HMQC) and heteronuclear multiple bond connectivity (HMBC) experiments. These compounds $\mathbf{1}-\mathbf{7}$ had already been identified by Didier and Bernard. ${ }^{1)}$ If steam distillation was not used, compound $\mathbf{8}$ was not found out. Therefore, it was considered that compound 8 might be formed by the thermal decomposition of compound $\mathbf{1}$ during the steam distillation. ${ }^{9}$

To determine the antiallergic properties of these compounds, the study of histamine release from rat peritoneal mast cells induced by compound 48/80 in rats was used. As shown in Fig. 2, the histamine release in the control group induced by compound $48 / 80(0.5 \mu \mathrm{g} / \mathrm{ml})$ was $36.8 \pm 4.4 \%$ $(n=6)$ of the total content. Compound 4 dose-dependently inhibited the histamine release and significant differences

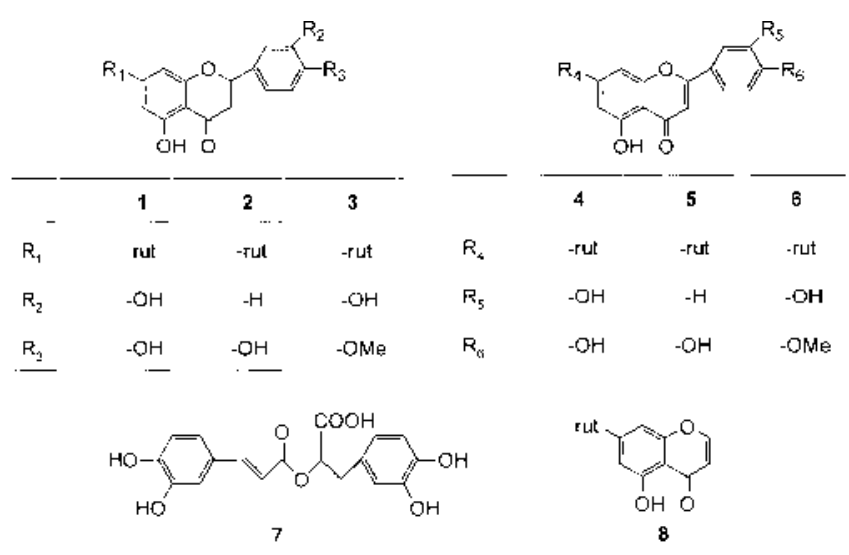

Fig. 1. The Chemical Structures of Compounds $\mathbf{1}-\mathbf{8}$ 

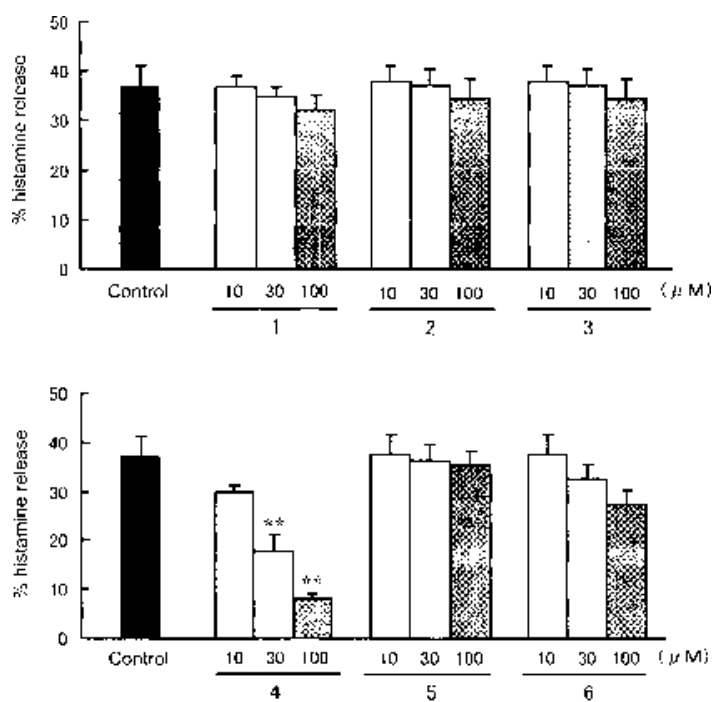

Fig. 2. Effects of Compounds $\mathbf{1}-\mathbf{6}$ on Histamine Release from Rat Peritoneal Mast Cells Induced by Compound 48/80 $(0.5 \mu \mathrm{g} / \mathrm{ml})$

Each column and vertical bar represents the mean \pm S.E.M. for 6 animals. **; $p<0.01$ compared with the control group (Dunnett's test).

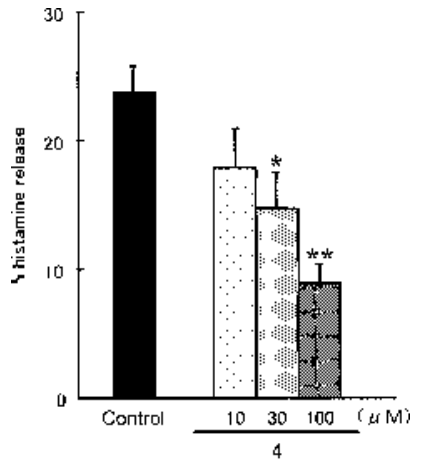

Fig. 3. Effect of Compound $\mathbf{4}$ on Histamine Release from Rat Peritoneal Mast Cells Induced by Antigen

Each column and vertical bar represents the mean \pm S.E.M. for 8 animals. $* ; p<0.05$ and $* * ; p<0.01$ compared with the control group (Dunnett's test).

were observed at concentrations of $30 \mu \mathrm{M}$ or more. However, the other compounds had no effect on the histamine release even at a dose of $100 \mu \mathrm{M}$. Moreover, compound 4 showed the dose-dependent inhibition on histamine release induced by antigen and significant differences were observed at $30 \mu \mathrm{M}$ or more (Fig. 3). Kimata et al. reported that luteolin, which is the aglycon of compound 4, is a potent inhibitor of human mast cell activation induced by stimulation of A23187 and antihuman IgE. ${ }^{10)}$ As shown in rat present study, compound 4 also showed an inhibition of histamine release induced by compound 48/80 and antigen from peritoneal mast cells. In addition, Amellal et al. have reported that the catechol structure in the $\mathrm{B}$ ring and the $\mathrm{C} 2-\mathrm{C} 3$ double bond in the $\mathrm{C}$ ring is essential for the inhibition of the histamine release. ${ }^{11)}$ Therefore, it seems reasonable that compound $\mathbf{4}$ had a potent inhibitory effect on the histamine release from rat peritoneal mast cells. However, the role of the sugar moiety at the C-7 position is unclear. The effects of the sugar moiety attached to the $\mathrm{C}-7$ position in the A ring were then studied by using aglycon (luteolin) and the compounds having a sugar at the $\mathrm{C}-7$ position of luteolin (luteolin-7-O-glucoside and com-
Table 1. $\mathrm{IC}_{50}$ Values of Different Flavonoids for the Histamine Release from Rat Peritoneal Mast Cells Induced by Compound 48/80 $(0.5 \mu \mathrm{g} / \mathrm{ml})$

\begin{tabular}{lc}
\hline \hline \multicolumn{1}{c}{ Compounds } & $\mathrm{IC}_{50}$ values $\left(\begin{array}{c}95 \% \text { confidence limits }) \\
(\mu \mathrm{M})\end{array}\right.$ \\
\hline Luteolin & $54.4(54.2-54.6)$ \\
Luteolin-7-O-glucoside & $41.6(32.2-51.0)$ \\
Compound 4 (luteolin-7-O-rutinoside) & $21.9(19.9-24.1)$ \\
\hline
\end{tabular}
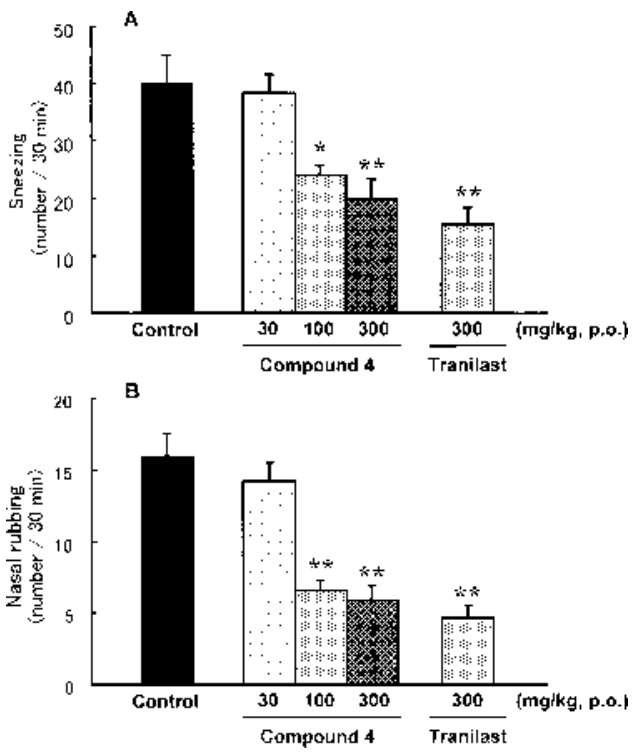

Fig. 4. Effects of Compound 4 on Sneezing (A) and Nasal Rubbing (B) Induced by Antigen in Rats

Each column and vertical bar represents the mean \pm S.E.M. for 9 animals. $* ; p<0.05$ and $* * ; p<0.01$ compared with the control group (Dunnett's test).

pound 4). As a result, luteolin, luteolin-7-O-glucoside and compound 4 caused a dose-dependent inhibition of histamine release. $\mathrm{The} \mathrm{IC}_{50}$ value for the luteolin was 54.4 (54.2 - 54.6) $\mu \mathrm{M}$. Compound 4 was more effective than luteolin and luteolin-7-O-glucoside in inhibiting histamine release (Table 1). From these results, it is considered that the presence of the sugar moiety at the $\mathrm{C}-7$ position in the A ring might enhance the inhibition of histamine release.

Recently, we developed a new animal model for allergic rhinitis; sneezing and nasal rubbing in this model are useful for evaluating the effects of antiallergic drugs on allergic rhinitis. ${ }^{12)}$ Therefore, effects of the compound 4 on the antigen-induced nasal symptoms in rats were studied, and the results are shown in Fig. 4. The sneezing frequency in the control induced by the antigen was $39.9 \pm 5.2$ times $/ 30 \mathrm{~min}$. Compound 4 caused a dose-related inhibition of this response and significant effects were observed at doses of 100 and $300 \mathrm{mg} / \mathrm{kg}$. Tranilast inhibited the antigen-induced sneezing at a dose of $300 \mathrm{mg} / \mathrm{kg}$. Nasal rubbing was also significantly inhibited by compound 4 at doses of $100 \mathrm{mg} / \mathrm{kg}$ or more. Tranilast significantly inhibited this response at a dose of $300 \mathrm{mg} / \mathrm{kg}$. In summary, compound 4 caused an inhibition not only histamine release but also nasal symptoms induced by antigen. Therefore, it seems likely that antiallergic effects of compound $\mathbf{4}$ are attributable to antigen-antibody reaction.

Saito et al. proposed that chemical mediators, including histamine, released from the mast cells caused sneezing and 

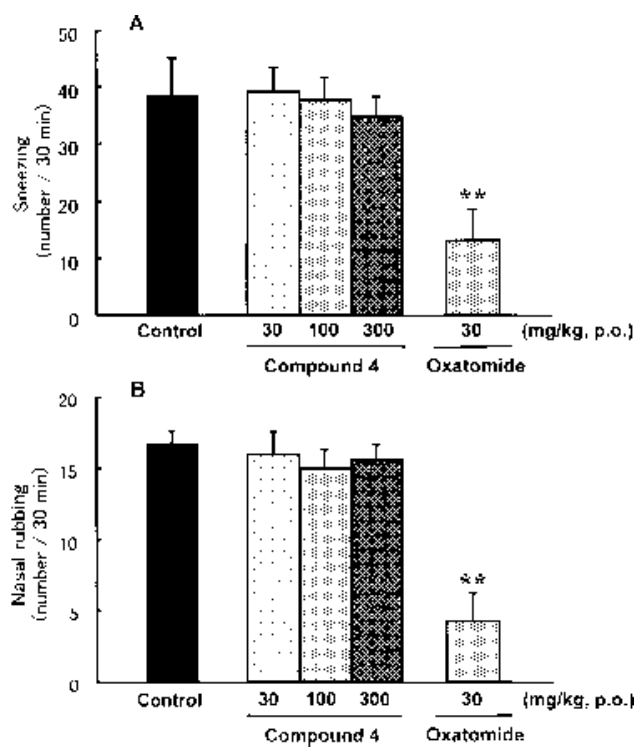

Fig. 5. Effects of Compound 4 on Sneezing (A) and Nasal Rubbing (B) Induced by Histamine $(10 \mu \mathrm{mol} / \mathrm{Site})$

Each column and vertical bar represents the mean \pm S.E.M. for 10 animals. **; $p<0.01$ compared with the control group (Dunnett's test).

nasal rubbing. ${ }^{13)}$ Therefore, whether or not compound 4 showed an inhibitory effect on sneezing and nasal rubbing induced by histamine in rats was studied. As shown in Fig. 5, compound 4 showed no significant effect on sneezing or nasal rubbing induced by histamine even at a dose of $300 \mathrm{mg} / \mathrm{kg}$. Oxatomide, which showed both anti-histaminergic activity and an inhibition of histamine release, ${ }^{14)}$ inhibited the histamine-induced sneezing at a dose of $30 \mathrm{mg} / \mathrm{kg}$.
However, compound 4 only showed an inhibited histamine release from rat peritoneal mast cells. Therefore, the inhibitory effects of compound $\mathbf{4}$ on sneezing and nasal rubbing induced by antigen challenge may be responsible for the inhibition of histamine release from mast cells in the nasal mucosa.

These results indicated that compound $\mathbf{4}$ is an active substance of Mentha piperita L. and may be effective in alleviating the nasal symptoms of allergic rhinitis in clinical trials.

\section{REFERENCES}

1) Didier J. G., Bernard P. P., J. Agric. Food Chem., 42, 679-684 (1994).

2) Juergens U. R., Stober M., Vetter H., Eur. J. Med. Res., 3, 539-545 (1998).

3) Tassou C. C., Drosinos E. H., Nychas G. J., J. Appl. Bacteriol., 78, 593-600 (1995).

4) Sarbhoy A. K., Varshney J. L., Maheshwari M. L., Saxena D. B., Zbl. Bakt. II, 133, 723-725 (1978).

5) Hoffmann B. G., Lunder L. T., Planta Med., 50, 361 (1984).

6) Duband F., Carnat A. P., Carnat A., Petitjean-Freytet C., Clair G., Lamaison J. L., Ann. Pharm Fr., 50, 146-155 (1992).

7) Inoue T., Sugimoto Y., Masuda H., Kamei C., Biol. Pharm. Bull., 24, 92-95 (2001).

8) Zhao Q. E., Mihara T., Sugimoto Y., Kamei C., Biol. Pharm. Bull., 19, 237-240 (1996).

9) Stoker M., Pohl R., Phytochemistry, 15, 571—572 (1976).

10) Kimata M., Shichijo M., Miura T., Serizawa I., Inagaki N., Nagai H., Clin. Exp. Allergy, 30, 501-508 (2000).

11) Amellal M., Bronner C., Briancon F., Haag M., Anton R., Landry Y., Planta Med., 1, 16-20 (1985).

12) Sugimoto Y., Kawamoto E., Chen Z., Kamei C., Immunopharmacology, 48, 1-7 (2000).

13) Saito H., Asakura K., Kataura A., Arerugi, 43, 579-584 (1994).

14) Patella V., de Crescenzo G., Marino O., Spadaro G., Genovese A., Marone G., Int. Arch. Allergy Immunol., 111, 23-29 (1996). 